\title{
Long non-coding RNA profile revealed by microarray indicates that IncCUEDC1 serves a negative regulatory role in breast cancer stem cells
}

\author{
FENGCHUN ZHANG ${ }^{1,2^{*}}$, YUE MA $^{3 *}$, LIANG XU ${ }^{4}$, HAIYAN XU ${ }^{1}$, YINGCHUN XU $^{3}$ and NINGNING YAN ${ }^{5}$ \\ ${ }^{1}$ Department of Oncology, Suzhou Kowloon Hospital, Shanghai Jiaotong University School of Medicine, Suzhou, \\ Jiangsu 215021; ${ }^{2}$ Department of Oncology, Ruijin Hospital, Shanghai Jiaotong University School of Medicine, \\ Shanghai 200025; ${ }^{3}$ Department of Oncology, Renji Hospital, Shanghai Jiaotong University School of Medicine,
} Shanghai 200127; ${ }^{4}$ The First Department of Prevention and Cure Centre of Breast Disease, The Third Hospital of Nanchang City, Nanchang, Jiangxi 330009; ${ }^{5}$ Department of Oncology, The First Affiliated Hospital of Zhengzhou University, Zhengzhou, Henan 450002, P.R. China

Received June 13, 2019; Accepted November 29, 2019

DOI: $10.3892 /$ ijo.2020.4960

\begin{abstract}
Previous studies have demonstrated that long non-coding RNAs (lncRNAs) are involved in breast cancer development, progression and metastasis. However, the association between lncRNAs and breast cancer stem cells (BCSCs) has been poorly explored. To address this issue, microarray analyses were performed to detect the lncRNA profile of BCSCs. In addition, bioinformatics analyses, including Gene Ontology and the Kyoto Encyclopedia of Genes and Genomes pathway analyses, were performed to explore the functional roles of IncRNAs in BCSCs. Lastly, loss of function assays were used to explore the potential function of lncRNA CUE domain containing 1 (lncCUEDC1). A total of 142 differentially expressed lncRNAs were identified. Among these, 25 were downregulated and 117 were upregulated in BCSCs compared with in non-BCSCs. In addition, the present study revealed that the IncRNAs were largely associated with stemness-related signaling pathways. Furthermore, it was demonstrated that IncCUEDC1 negatively regulated the phenotype and biological functions of BCSCs in vitro. Mechanistically, lncCUEDC1 could bind NANOG to inhibit
\end{abstract}

Correspondence to: Dr Ningning Yan, Department of Oncology, The First Affiliated Hospital of Zhengzhou University, 1 East Jianshe Road, Zhengzhou, Henan 450002, P.R. China

E-mail: yanningrj@163.com

Dr Yingchun $\mathrm{Xu}$, Department of Oncology, Renji Hospital, Shanghai Jiaotong University School of Medicine, 160 Pujian Road, Shanghai 200127, P.R. China

E-mail: xiaoxu2384@163.com

*Contributed equally

Key words: long non-coding RNAs, breast cancer stem cells, microarray, lncCUEDC1 the stemness. To the best of our knowledge, the present study was the first to established the IncRNA profile of BCSCs. These findings provided evidence for exploring the functions of lncRNAs in BCSCs and indicated that lncCUEDC1 is a prospective target in BCSCs.

\section{Introduction}

Breast cancer is the most commonly diagnosed cancer and the second leading cause of cancer-associated death among women in the USA (1). With the development of more efficient treatments and techniques for early diagnosis, cancer mortality has been greatly reduced. Nevertheless, the occurrence of cancer recurrence, metastasis and treatment failure remains inescapable (2). Therefore, it is critical to identify the underlying mechanisms of breast cancer progression and metastasis. Currently, there is increasing evidence that cancer stem cells (CSCs) are a major cause of breast cancer recurrence, metastasis and treatment resistance (3-5).

According to the CSC hypothesis, CSCs are a subset of tumor cells that are capable of developing new tumors via dysfunction of the self-renewal progress (6). Under normal conditions, the self-renewal capacity of CSCs is governed by several critical signaling pathways, including the Wnt, Notch and sonic hedgehog signaling pathways (7). However, should the normal regulatory mechanisms become disordered, they may also contribute to sustaining the behaviors of CSCs (7-10). Due to the control of the aforementioned signaling pathways in both normal stem cells and CSCs, CSC-targeted therapies specific to these pathways will inevitably result in substantial toxicity. Therefore, novel targets for eliminating CSCs are urgently required.

Long non-coding RNAs (lncRNAs) are characterized as functional RNAs that are $>200$ nucleotides long and do not have a protein-coding capacity $(11,12)$. In general, lncRNAs are linked to diverse biological processes, such as cell proliferation, differentiation and apoptosis, which allows them to serve as gene modulators (12-15). In addition to biological 
processes, several studies have revealed that dysregulated IncRNAs are closely associated with a number of human diseases, including breast cancer (16-18). For example, HOX transcript antisense RNA (HOTAIR), which is a well-studied lncRNA, has been demonstrated to be aberrantly expressed during breast cancer progression (19). In addition, the global level of HOTAIR is enhanced in breast cancer metastasis and could serve as a strong predictor of this event (19). Additionally, a previous study has demonstrated that the lncRNA urothelial carcinoma-associated 1 could serve as an oncogene in breast cancer (20). Conversely, some lncRNAs seem to act as tumor suppressors in breast cancer. Growth arrest-specific transcript 5 serves a vital role in controlling apoptosis and cell proliferation. Its transcript level is remarkably decreased in breast cancer tissues relative to adjacent normal tissues (21). These reports collectively indicate that lncRNAs may exert both positive and negative effects in breast cancer. However, the expression profile, function and regulation of lncRNAs in breast cancer stem cells (BCSCs) remain to be identified. The present study analyzed the expression profile of lncRNAs in BCSCs and matched non-BCSCs. Subsequently, the possible functions and potential involved pathways of the identified lncRNAs were analyzed using bioinformatics. Some stemness-related pathways were closely associated with the lncRNAs. In addition, a lncRNA-mRNA interaction network was constructed to further determine the possible functions. IncRNA CUE domain containing 1 (lncCUEDC1; lncRNA id, ENST00000584746) was significantly downregulated and exhibited a negative regulatory effect in BCSCs. Collectively, the present study provided a substantial foundation for studying the roles of IncRNAs in BCSCs and evidence for novel approaches to target BCSCs.

\section{Materials and methods}

Antibodies. Rabbit monoclonal anti-Sox2 (cat. no. 3579S), anti-Nanog (cat. no. 4903S) and anti-GAPDH (cat. no. 5174S) antibodies, and polyclonal anti-Oct4 (cat. no. 2750S) antibodies used for western blotting were purchased from Cell Signaling Technology, Inc. Goat anti-rabbit horseradish peroxidase-conjugated immunoglobulin G (cat. no. sc-2004) was obtained from Santa Cruz Biotechnology, Inc. PE-conjugated CD24 (cat. no. 130-095-953) and FITC-conjugated CD44 (cat. no. 130-095-195) antibodies used for fluorescence-activated cell sorting (FACS) were purchased from Miltenyi Biotec, Inc.

Cell culture. Human MCF-7, MDA-MB-231 breast cancer cells and 293T cells were obtained from the American Type Culture Collection and cultured in the recommended media according to standard methods. Briefly, MCF7 cells and 293T cells were cultured at $37^{\circ} \mathrm{C}$ in a humidified atmosphere with $5 \% \mathrm{CO}_{2}$ in DMEM (HyClone; GE Healthcare Life Sciences), whereas MDA-MB-231 cells were cultured under the same conditions in DMEM (HyClone; GE Healthcare Life Sciences), but without $\mathrm{CO}_{2}$. In addition, all media were supplemented with $10 \% \mathrm{FBS}$ (Gibco: Thermo Fisher Scientific, Inc.), $100 \mathrm{U} / \mathrm{ml}$ penicillin (Gibco; Thermo Fisher Scientific, Inc.) and $100 \mathrm{mg} / \mathrm{ml}$ streptomycin (Gibco; Thermo Fisher Scientific, Inc.). Cells were passaged upon reaching $90 \%$ confluence.
Mammosphere formation assay. The mammosphere culture platform has been previously established (22). Briefly, adherent cells were digested with trypsin (Gibco; Thermo Fisher Scientific, Inc.) into a single-cell suspension at a concentration of $10^{4}$ cells $/ \mathrm{ml}$. Subsequently, the cells were plated in ultra-low attachment 6-well plates and maintained in DMEM/F12 (1:1; Gibco; Thermo Fisher Scientific, Inc.) supplemented with 50X B27 (Invitrogen; Thermo Fisher Scientific, Inc.), 20 ng/ml human basic fibroblast growth factor (Gibco; Thermo Fisher Scientific, Inc.), $20 \mathrm{ng} / \mathrm{ml}$ human epidermal growth factor (Gibco; Thermo Fisher Scientific, Inc.) and $5 \mu \mathrm{g} / \mathrm{ml}$ human insulin (Sigma-Aldrich; Merck KGaA). The medium was replaced every 3 days, and on day 7 significant mammospheres (diameter, $\geq 100 \mu \mathrm{m}$ ) were observed under a light microscope at x40 magnification.

Colony formation assay. Breast cancer cells were detached and resuspended in a single-cell suspension. Subsequently, 400 cells were inoculated into a 6-well plate and cultured in DMEM containing 10\% FBS, $100 \mathrm{U} / \mathrm{ml}$ penicillin and $100 \mathrm{mg} / \mathrm{ml}$ streptomycin. On day 14, the colonies were imaged under a light microscope.

Flow cytometry analysis. Mammosphere cells were harvested on day 7 and resuspended in a single-cell suspension with flow cytometry buffer (1X PBS containing $2.5 \%$ FBS) without blocking. The suspension was incubated with anti-CD44 (dilution, 1:100) and anti-CD24 (dilution, 1:100) antibodies according to the manufacturer's protocols. The stained cells were sorted with a FACSAria system (BD Biosciences) and divided into two groups: $\mathrm{CD} 44^{+} \mathrm{CD} 24^{-}$cells (BCSCs) and non-CD $44^{+} \mathrm{CD} 24^{-}$cells (non-BCSCs). FlowJo software was used for data analysis (version 7.6; FlowJo LLC) and 20,000 cells were included in the analysis.

Microarray analysis. The GeneChip ${ }^{\circledR}$ Human Exon 1.0 ST Array (Affymetrix; Thermo Fisher Scientific, Inc.) is designed for screening lncRNAs and protein coding transcripts in BCSCs. The chips can be used to investigate 44,414 human lncRNAs and 22,012 human mRNAs. These IncRNAs were screened with several databases, including RefSeq (https://www.ncbi.nlm.nih.gov/refseq/), GENCODE/ENSEMBLE (http://ensembl.org/index.html), NONCODE (http://www.noncode.org/) and UCSC Genome Browser (http://genome.ucsc.edu/). Briefly, total RNA was transcribed into cDNA and labelled with GeneChip2 WT Terminal Labelling kit and Controls kit (Affymetrix; Thermo Fisher Scientific, Inc.). Subsequently, the samples were hybridized overnight at $45^{\circ} \mathrm{C}$ and washed with washing buffer (Affymetrix; Thermo Fisher Scientific, Inc.). The chips were scanned using the Affymetrix GeneChip Command Console with default settings (Affymetrix; Thermo Fisher Scientific, Inc.). Data were collected with the Affymetrix Launcher (version 1.0; Affymetrix; Thermo Fisher Scientific, Inc.).

Data analysis. Data summarization, normalization and quality control were carried out using GeneSpring software v13.0 (Agilent Technologies, Inc.). For hierarchical clustering, differentially expressed genes were selected according to the following criteria: Fold change $\geq 2$ and $\mathrm{P}<0.05$. Subsequently, 
the fold change was $\log _{2}$-transformed, and the data were visualized by generating a heatmap in Java TreeView (version 6; https://sourceforge.net/projects/jtreeview/). Finally, two-way hierarchical clustering analysis (Cluster Profiler; V3.6; http://www.bioconductor.org/packages/release/bioc/html/clusterProfiler.html) was applied to categorize the samples with similar gene expression patterns and reveal associations between the samples.

Gene Ontology (GO) enrichment and Kyoto Encyclopedia of Genes and Genomes (KEGG) pathway analysis. To the best of our knowledge, the majority of the identified lncRNAs have not yet been functionally characterized. Therefore, their functionalities can only be predicted by analyzing their mRNA counterparts (23). Accordingly, GO (http://geneontology.org/) and KEGG analyses (https://www.genome.jp/kegg/pathway. html) were performed to explore the corresponding mRNA functions using R software (version 3.4.3; https://www.r-project. org/). Distinct GO categories were considered statistically significant with $\mathrm{P}<0.05$. The $\mathrm{P}$-values shown in the KEGG pathway analyses represent the significance of the pathways.

lncRNA-mRNA network. Crosstalk between lncRNAs and mRNAs was established as previously described (24). Briefly, the interaction network was built based on the normalized signal intensity of the expression of specific mRNAs and lncRNAs. Correlations between the aberrantly expressed lncRNAs and their reciprocal genes were calculated to select significantly correlated pairs with which the network was constructed.

Reverse transcription-quantitative PCR (RT-qPCR). To validate the microarray results, six lncRNAs were randomly selected for RT-qPCR, which was performed using the FastStart Universal SYBR-Green Master kit (Roche Diagnostics) according to the manufacturer's protocols on an ABI PRISM 7900HT sequence detection system (Applied Biosystems; Thermo Fisher Scientific, Inc.). Total RNA extraction was performed with TRIzol ${ }^{\circledR}$ reagent (Invitrogen; Thermo Fisher Scientific, Inc.) according the manufacturer's protocol, and reverse transcription was performed using Super-Script II (Takara Bio, Inc.) according to the manufacturer's protocol. The RT-qPCR protocol was as follows: $2 \mathrm{~min}$ at $50^{\circ} \mathrm{C}$, followed by $10 \mathrm{~min}$ at $95^{\circ} \mathrm{C}$ and 40 cycles of PCR following standard conditions with $15 \mathrm{sec}$ of denaturation at $95^{\circ} \mathrm{C}$, elongation at $60^{\circ} \mathrm{C}$ for $1 \mathrm{~min}, 95^{\circ} \mathrm{C}$ for $15 \mathrm{sec}$ and $1 \mathrm{~min}$ at $60^{\circ} \mathrm{C}$, and extension at $72^{\circ} \mathrm{C}$ for $5 \mathrm{~min}$. GAPDH was used as an internal control, and the relative expression levels were analyzed by the $2^{-\Delta \Delta \mathrm{Cq}}$ method (25). All primers were designed using primer premier 5 (Premier Biosoft International) and are listed in Table I.

Sanger sequencing. PCR products were resolved on a $1.2 \%$ agarose gel containing GelRed Nucleic Acid Gel stain (Yeasen). The products were confirmed by Sanger sequencing (Sangon Biotech Co., Ltd.).

Western blotting. Total protein was extracted from mammosphere cells and adherent cells, which were collected and lysed in RIPA buffer (Invitrogen; Thermo Fisher Scientific, Inc.). The extracted protein was subjected to BCA buffer (Invitrogen; Thermo Fisher Scientific, Inc.) for protein quantity analysis. Equal amounts $(20 \mu \mathrm{g} / \mathrm{lane})$ of protein were separated by $10 \%$ SDS-PAGE and transferred onto a PVDF membrane (EMD Millipore). Subsequently, the membranes were blocked with 5\% BSA (Sigma-Aldrich; Merck KGaA) at room temperature for $1 \mathrm{~h}$. The membranes were incubated with primary antibodies (dilution, 1:1,000) overnight at $4^{\circ} \mathrm{C}$, and GAPDH served as the loading control. After the membranes were incubated with secondary antibodies (dilution, 1:5,000) at $37^{\circ} \mathrm{C}$ for $1 \mathrm{~h}$, they were subjected to ECL Prime Western Blotting Detection reagent (Invitrogen; Thermo Fisher Scientific, Inc.). The immunoreactive bands were visualized using a LAS-3000 Imager (Fujifilm).

Silencing of lncCUEDC1. LncCUEDC1 small interfering RNA (siRNA) was synthesized by Shanghai GenePharma Co., Ltd. MCF-7 and MDA-MB-231 cells were transfected with 20 pmol lncCUEDC1 siRNA or negative control (NC) using Lipofectamine ${ }^{\circledR} 2000$ (Invitrogen; Thermo Fisher Scientific, Inc.). Subsequent experiments were performed after transfection for $48 \mathrm{~h}$. The lncCUEDC1 and NC siRNA sequences were as follows: 1ncCUEDC1 forward, 5'-CCAGAGGCUUCUCAA CUUUTT and reverse, 5'-AAAGUUGAGAAGCCUCUG GTT; NC forward, 5'-UUCUCCGAACGUGUCACGUTT and reverse, 5'-ACGUGACACGUUCGGAGAATT.

Fluorescence in situ hybridization (FISH). In situ hybridization was performed according to the fluorescent in situ hybridization kit instructions (cat. no. C1090; Guangzhou RiboBio Co., Ltd.). Briefly, breast cancer cells were digested into a single-cell suspension and seeded on glass coverslips. Subsequently, the cells were fixed with $4 \%$ paraformaldehyde for $10 \mathrm{~min}$ at $4^{\circ} \mathrm{C}$ and permeabilized with $0.5 \%$ Triton $\mathrm{X}-100$ (Biosharp) for $5 \mathrm{~min}$ at $4^{\circ} \mathrm{C}$. After blocking for $30 \mathrm{~min}$ at $37^{\circ} \mathrm{C}$, the cells were inoculated with a $\mathrm{Cy} 3$ labeled lncCUEDC1 FISH probe overnight at $37^{\circ} \mathrm{C}$, all blocking and hybridization buffers were included in the FISH kit. The images were captured under a fluorescence microscope (Carl Zeiss AG) and were analyzed with Photoshop (version 6.0; Adobe Systems, Inc.).

Luciferase reporter assay. Luciferase reporter assays were performed according to the instructions of the Pierce ${ }^{\mathrm{TM}}$ Renilla-Firefly Luciferase Dual Assay kit (cat. no. 16186; Thermo Fisher Scientific, Inc.). Specifically, green Renilla luciferase acted as an experimental reporter with constitutively active red firefly as a normalization control. NANOG (1-512 bp) was amplified by PCR and inserted into the psiCHECK2.0 vector (psiCHECK2.0 vector; Addgene, Inc.). Full length lncCUEDC1 was cloned into the pcDNA 3.1 vector. Subsequently, 293T cells were co-transfected with NANOG and 1ncCUEDC1 using Lipofectamine ${ }^{\circledR} 2000$ (Invitrogen; Thermo Fisher Scientific, Inc.) for $48 \mathrm{~h}$. Cells were collected and used to perform the luciferase reporter assay according to the manufacturer's protocols. Luciferase activity was measured using a microplate reader (Tecan Group, Ltd.).

Statistical analysis. All data were analyzed using Prism v6 (GraphPad Software, Inc.), unless otherwise specified. 
Independent-sample t-testing was used to compare the global levels of lncRNAs between the different groups. Fisher's exact test was applied in GO and KEGG analysis. Data are presented as the mean \pm SD of three independent experiments. $\mathrm{P}<0.05$ was considered to indicate a statistically significant difference.

\section{Results}

Mammosphere-derived cells exhibit a relatively higher proportion of cells with the $C D 44^{+} C D 24$ phenotype. A commonly used method, the mammosphere formation assay, was performed to enrich BCSCs (26). Mammospheres with diameters $\geq 100 \mu \mathrm{m}$ were considered significant (Fig. 1A). The results of the present study demonstrated that mammosphere-derived cells exhibited a higher percentage of BCSCs with the CD $44^{+} \mathrm{CD} 24^{-}$phenotype than adherent cells (Fig. 1B and C). Overall, these data validated the system used in the present study and supported the theory that the mammosphere culture assay is an effective method for enriching BCSCs.

In the present study, a GeneChip ${ }^{\circledR}$ Human Exon 1.0 ST Array was used to detect the lncRNA profile of BCSCs. A total of 44,414 human lncRNAs and 22,012 human mRNA candidates were identified in three pairs of samples. Additionally, 142 differentially expressed lncRNAs with a fold change $>2.5$ were identified between BCSCs and non-BCSCs. Among these, 117 were upregulated and 25 were downregulated (Fig. 2A). Additionally, the cluster of corresponding mRNAs is presented in Fig. 2B. The information regarding the differentially expressed lncRNA is listed in Table II by fold change.

Characteristics of identified lncRNAs. To better define the identified lncRNAs, lncRNAs expression characteristics, including their classification, chromosome distribution and length distribution, were analyzed. The present study demonstrated that the identified lncRNAs could be attributed to six classes, including natural 'antisense', 'up-downstream', 'UTR3-Alu RI' (UTR3 regulation), 'enhancer-like', '3'UTR-Alu repeat sequence' and 'nearby-effect', based on their position on the genome. The data revealed that most lncRNAs were located up-downstream of their mRNA counterparts (Fig. 3A) and that their lengths were mainly distributed between 301-600 and 601-900 nucleotides (Fig. 3B). These findings, including the length and chromosome location, partially agreed with those of a previous study (26). Furthermore, a chromosome distribution analysis revealed a difference in the chromosome distribution between upregulated lncRNAs and downregulated lncRNAs (Fig. 3C).

Validation of differentially expressed lncRNAs. Six lncRNAs, including lncRBM47, lncNONHSAT114469, lncGOPLH, lncCUEDC1, IncTMA16 and 1ncATG12, were randomly selected to validate the microarray results by qPCR, which confirmed that these IncRNAs were aberrantly expressed in mammosphere cells compared with in adherent cells (Fig. 4A and B). The $\log _{2}$-fold changes were used for analysing the microarray and qPCR results (Fig. 4C and D). The qPCR results were consistent with the results of the microarray assay. In addition, Sanger sequencing of lncCUEDC1, which was the most downregulated lncRNA, further validated the microarray data (Fig. 5). These findings indicated that these lncRNAs were differentially expressed between BCSCs and non-BCSCs.

Functional prediction analysis for identified lncRNAs. Previous studies have revealed that lncRNAs are generally transcribed along with their corresponding mRNAs and have the potential to modulate the expression of their adjacent genes in multiple manners $(28,29)$. In addition, the functions of IncRNAs are partially reflected by their counterpart mRNAs (30). Therefore, GO enrichment and KEGG pathway analyses were performed to predict the functions of identified lncRNAs. GO analysis of the upregulated and downregulated IncRNAs revealed that the most frequently enriched functions of lncRNAs were mainly associated with 'transcription', 'regulation of transcription', 'small molecule metabolic process' and 'cytokine-mediated signalling pathway' (Fig. 6A and B). Intriguingly, 'transcription' and 'regulation of transcription' were the two most significantly enriched terms for IncRNAs in BCSCs, which demonstrated that lncRNAs may be involved in regulating expression levels of stemness-related genes. In the KEGG pathway analysis, 142 aberrantly expressed lncRNAs were distributed among 305 KEGG pathways (Fig. 6C and D). Of these, the 'JAK-STAT signaling pathway', 'PI3K-Akt signaling pathway' and 'HIF-1 signaling pathway', all of which are associated with BCSC modulation, were found to be associated with the identified lncRNAs. Several studies have indicated that these signaling pathways serve critical roles in stem cell behavior (31-33). These findings suggested that lncRNAs could be implicated in BCSCs behaviors.

lncRNA-mRNA co-expression network. To further decipher the functionalities of the lncRNAs identified here, a lncRNA-mRNA co-expression network was constructed based on correlation analysis (34). The crosstalk between lncRNAs and mRNAs is shown in Fig. S1. In addition, the interaction network revealed that lncCUEDC1 could interact with Musashi 2 (MSI2). Overall, these findings suggested that lncRNAs may control BCSCs by modulating the expression of their corresponding mRNAs.

lncCUEDC1 exhibits inhibitory effects on BCSCs. Based on the results, it was postulated that 1 ncCUEDC1 may serve an inhibitory role in BCSCs. Hence, siRNAs targeting lncCUEDC1 were designed to validate this hypothesis and explore its effect on BCSCs behavior and stemness. After knocking down the expression of lncCUEDC1 using siRNA, the expression levels of stemness-related markers were greatly enhanced compared with those in cells transfected with the $\mathrm{NC}$ siRNA at the mRNA and protein levels (Fig. 7A-C). Additionally, breast cancer cells transfected with lncCUEDC1 siRNA exhibited a substantial increase in the proportion of CD $44^{+}$CD24- BCSCs compared with cells transfected with the NC (Fig. 7D and E). Additionally, mammosphere and colony formation capacities were increased in cells transfected with lncCUEDC1 siRNA (Fig. 7F-I). Overall, these data suggested that 1 ncCUEDC1 could suppress BCSCs 
A

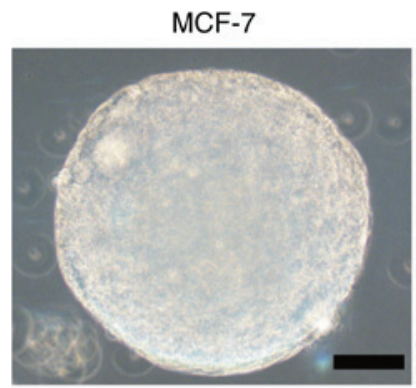

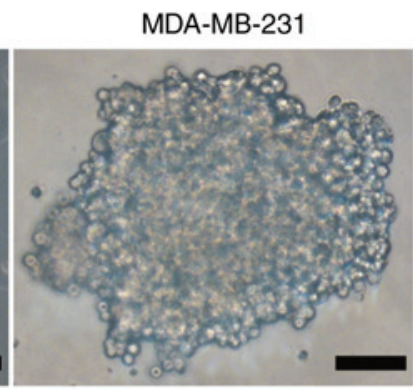

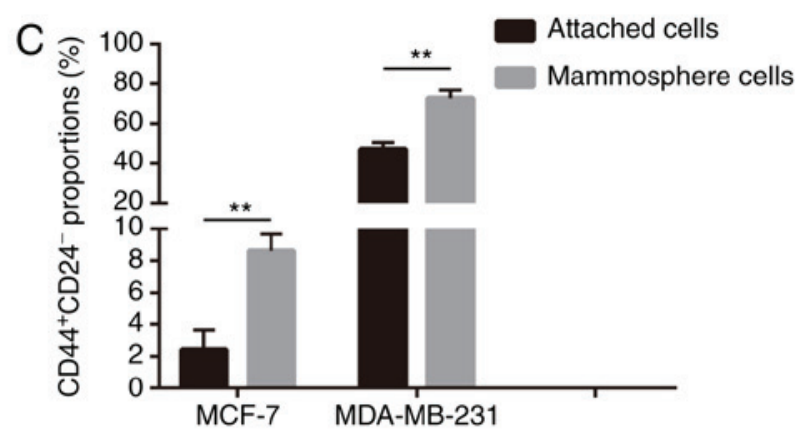

B

MCF-7

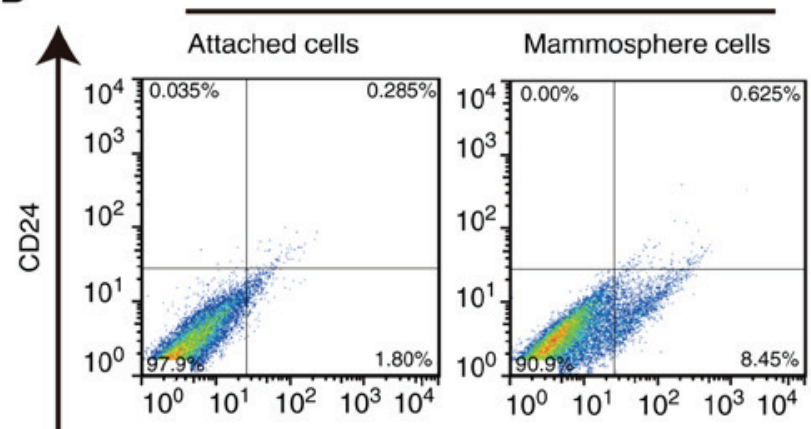

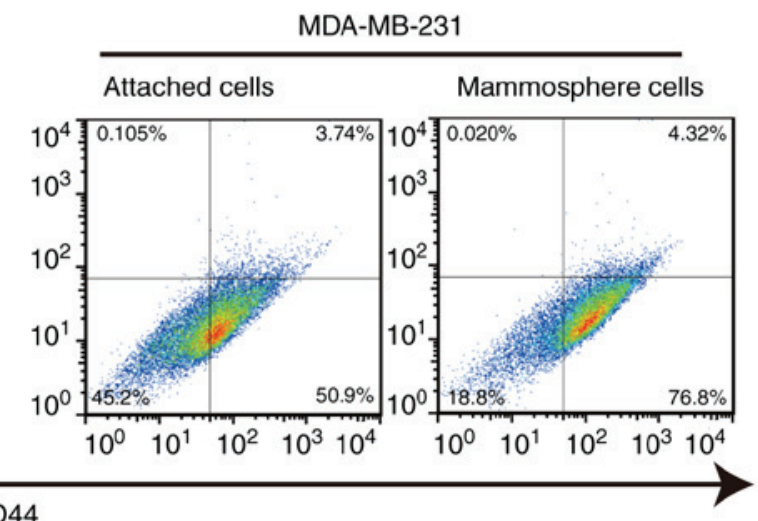

Figure 1. Mammosphere cells exhibit a higher frequency of CD44+CD24- BCSCs. (A) Phase-contrast images of mammospheres derived from $\mathrm{MCF}-7$ and MDA-MB-231 cells. (B) Flow cytometry analysis for mammosphere cells and adherent cells. (C) Mammosphere cells exhibited a higher percentage of $\mathrm{CD} 44^{+} \mathrm{CD} 24{ }^{-} \mathrm{BCSC}$ s than adherent cells. Data are presented as the mean $\pm \mathrm{SD}$ of three independent assays. ${ }^{* *} \mathrm{P}<0.01$, as indicated. BCSC, breast cancer stem cell.
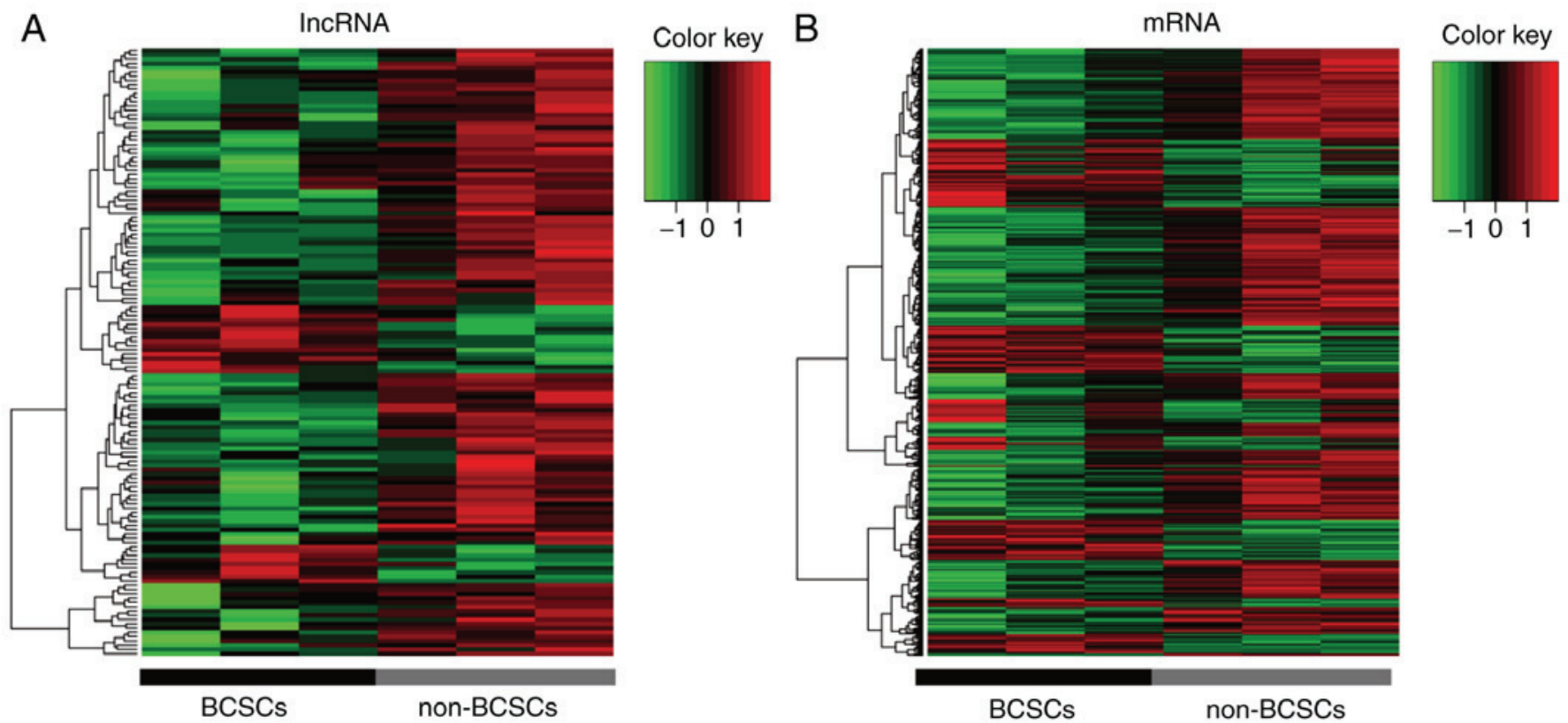

Figure 2. Hierarchical clustering graph of aberrantly expressed mRNAs and lncRNAs between BCSCs and non-BCSCs. (A) Differentially expressed lncRNAs in BCSCs. (B) Differentially expressed mRNAs in BCSCs. BCSC, breast cancer stem cell; lncRNA, long non-coding RNA.

stemness, which supports the potential of $\operatorname{lncCUEDC1}$ as a target for eliminating BCSCs.

To explore the mechanism by which 1 ncCUEDC1 regulates stemness,FISH assays were performed to determine the location of lncCUEDC1. The data demonstrated that lncCUEDC1 was mainly located in the cell nucleus. Notably, lncCUEDC1 could bind with Nanog in the nucleus (Fig. 8A and B). Additionally, the data revealed that the ectopic expression of IncCUEDC1 
Table I. List of primers.

\begin{tabular}{|c|c|}
\hline Gene & Primer sequences $\left(5^{\prime}-3^{\prime}\right)$ \\
\hline \multirow[t]{2}{*}{ RBM47 } & F: TATAGGCATGAGCCACCACA \\
\hline & R: AGCGCCCACTATTTACAAGG \\
\hline \multirow[t]{2}{*}{ NONHSAT114469 } & F: TGCACCTCTACACCCAGCTA \\
\hline & R: TCACACCTGTAATCCCAGCA \\
\hline \multirow[t]{2}{*}{ GOLPH } & F: TGCAGTTAGGTTTGCTAGGC \\
\hline & R: TGGTTAGAGCACAATTCTAAGACC \\
\hline \multirow[t]{2}{*}{ CUEDC1 } & F: ACTTTCACCCAGTCCСТTCC \\
\hline & R: GCCCTTCCAGTCCTTGTTTC \\
\hline \multirow[t]{2}{*}{ TMA16 } & F: CTGCATATTACAGAACCCATCTG \\
\hline & R: TTCCTTTAAGCACCTCAATGTC \\
\hline \multirow[t]{2}{*}{ ATG12 } & F: TCCTGCTTCATTTGCCTGTA \\
\hline & R: GCACACAGCCAAAAATCAAT \\
\hline \multirow[t]{2}{*}{ NANOG } & F: AAAGCCTCCCAATCCCAAACA \\
\hline & R: GCGGGCTCAATTTATAGAAACCGGG \\
\hline \multirow[t]{2}{*}{ GAPDH } & F: GGAGCGAGATCCCTCCAAAAT \\
\hline & R: GGCTGTTGTCATACTTCTCATGG \\
\hline \multirow[t]{2}{*}{ SOX2 } & F: TACAGCATGTCCTACTCGCAG \\
\hline & R: GAGGAAGAGGTAACCACAGGG \\
\hline \multirow[t]{2}{*}{ OCT4 } & F: GCCGCTGGCTTATAGAAGGT \\
\hline & R: CTCTCCCCAGCTTGCTTTGA \\
\hline
\end{tabular}

F, forward; R, reverse.

could inhibit the expression of Nanog but not psiCHECK2.0 in a luciferase reporter assay (Fig. 8C). Our previous study confirmed that Nanog could stimulate the stemness of breast cancer cells (35). Hence, the current data indicated that lncCUEDC1 may inhibit stemness by inhibiting Nanog, which needs to be further investigated.

\section{Discussion}

Accumulating evidence has demonstrated that lncRNAs serve critical roles in regulating cancer, including breast cancer, and that lncRNAs can act as either oncogenes or tumor suppressors. For example, a well-characterized lncRNA, H19, has been found to be an oncogene in breast cancer. In vitro experiments have shown that H19 is upregulated in breast cancer cells during the S-phase and that forced H19 expression could promote breast cancer cell proliferation (36). Additionally, another study has revealed that lncRNA-ROR is upregulated in breast tumor tissue samples and enhances the migration and invasion capacity of breast cancer cells (37). However, there remain contradictory conclusions regarding the functional roles of lncRNAs in breast cancer. Liu et al (18) demonstrated that an NF- $\kappa \mathrm{B}$-interacting lncRNA, NKILA, could suppress $\mathrm{NF}-\kappa \mathrm{B}$ activation to inhibit breast cancer metastasis. Reports on breast cancer are abundant, yet there is no systematic research on the lncRNA profile of BCSCs.

The present study first established a mammosphere platform. MDA-MB-231 cells seemed to be enriched with
Table II. Differentially expressed lncRNAs in breast cancer stem cells.

\begin{tabular}{|c|c|c|c|}
\hline lncRNA_id & P-value & $\begin{array}{l}\text { Fold } \\
\text { change }\end{array}$ & $\begin{array}{l}\text { Upregulation or } \\
\text { downregulation }\end{array}$ \\
\hline ENST00000584746 & 0.005225 & 0.33 & Down \\
\hline ENST00000531648 & 0.000236 & 0.34 & Down \\
\hline NONHSAT 118570 & 0.001455 & 0.35 & Down \\
\hline NONHSAT060713 & 0.005342 & 0.35 & Down \\
\hline ENST00000565771 & 0.003509 & 0.36 & Down \\
\hline ENST00000332858 & 0.004131 & 0.36 & Down \\
\hline ENST00000553466 & 0.006265 & 0.36 & Down \\
\hline ENST00000450469 & 0.008614 & 0.36 & Down \\
\hline ENST00000590962 & 0.009127 & 0.36 & Down \\
\hline ENST00000466288 & 0.000708 & 0.37 & Down \\
\hline ENST00000583426 & 0.007507 & 0.37 & Down \\
\hline NONHSAT077496 & 0.008404 & 0.37 & Down \\
\hline ENST00000568635 & 0.030779 & 0.37 & Down \\
\hline NONHSAT032633 & 0.004160 & 0.38 & Down \\
\hline ENST00000467521 & 0.004415 & 0.38 & Down \\
\hline ENST00000426367 & 0.005238 & 0.38 & Down \\
\hline ENST00000528553 & 0.006575 & 0.38 & Down \\
\hline NONHSAT078914 & 0.009508 & 0.38 & Down \\
\hline ENST00000559600 & 0.011918 & 0.38 & Down \\
\hline NONHSAT030084 & 0.001486 & 0.39 & Down \\
\hline ENST00000505899 & 0.001553 & 0.39 & Down \\
\hline NONHSAT127846 & 0.002345 & 0.39 & Down \\
\hline NONHSAT022603 & 0.005557 & 0.39 & Down \\
\hline ENST00000496353 & 0.007553 & 0.39 & Down \\
\hline NONHSAT 107636 & 0.018664 & 0.39 & Down \\
\hline NONHSAT032003 & 0.001439 & 2.51 & Up \\
\hline ENST00000553031 & 0.013427 & 2.51 & Up \\
\hline ENST00000480155 & 0.024014 & 2.51 & $\mathrm{Up}$ \\
\hline NONHSAT143607 & 0.028454 & 2.51 & Up \\
\hline ENST00000481059 & 0.004178 & 2.52 & Up \\
\hline ENST00000413961 & 0.005341 & 2.53 & Up \\
\hline ENST00000589496 & 0.015149 & 2.53 & Up \\
\hline ENST00000600535 & 0.025085 & 2.53 & Up \\
\hline ENST00000602510 & 0.015045 & 2.54 & Up \\
\hline NONHSAT074190 & 0.000795 & 2.55 & $\mathrm{Up}$ \\
\hline NONHSAT 102055 & 0.012780 & 2.55 & Up \\
\hline NONHSAT027878 & 0.048534 & 2.55 & Up \\
\hline NONHSAT112187 & 0.026605 & 2.56 & Up \\
\hline n346329 & 0.002635 & 2.57 & Up \\
\hline ENST00000542306 & 0.001966 & 2.58 & Up \\
\hline FR0049460 & 0.019297 & 2.58 & Up \\
\hline NONHSAT003589 & 0.001326 & 2.59 & Up \\
\hline n346329 & 0.006665 & 2.59 & Up \\
\hline ENST00000570137 & 0.018127 & 2.59 & Up \\
\hline FR0011909 & 0.006207 & 2.6 & Up \\
\hline ENST00000519690 & 0.014859 & 2.6 & Up \\
\hline NONHSAT138818 & 0.000899 & 2.61 & Up \\
\hline ENST00000492009 & 0.002426 & 2.61 & Up \\
\hline ENST00000429998 & 0.002882 & 2.61 & Up \\
\hline ENST00000558124 & 0.006331 & 2.62 & Up \\
\hline
\end{tabular}


Table II. Continued.

\begin{tabular}{|c|c|c|c|}
\hline lncRNA_id & P-value & $\begin{array}{c}\text { Fold } \\
\text { change }\end{array}$ & $\begin{array}{l}\text { Upregulation or } \\
\text { downregulation }\end{array}$ \\
\hline NONHSAT073839 & 0.004252 & 2.63 & $\mathrm{Up}$ \\
\hline ENST00000551655 & 0.016965 & 2.63 & $\mathrm{Up}$ \\
\hline ENST00000586718 & 0.012420 & 2.64 & Up \\
\hline ENST00000470108 & 0.012616 & 2.64 & $\mathrm{Up}$ \\
\hline ENST00000471763 & 0.001250 & 2.65 & Up \\
\hline ENST00000422822 & 0.003282 & 2.65 & Up \\
\hline NONHSAT115467 & 0.003438 & 2.66 & $\mathrm{Up}$ \\
\hline ENST00000515570 & 0.002535 & 2.67 & $\mathrm{Up}$ \\
\hline NONHSAT002344 & 0.003232 & 2.67 & Up \\
\hline NONHSAT114469 & 0.046724 & 2.68 & Up \\
\hline ENST00000478375 & 0.003936 & 2.69 & $\mathrm{Up}$ \\
\hline ENST00000487510 & 0.009022 & 2.69 & $\mathrm{Up}$ \\
\hline ENST00000589496 & 0.032779 & 2.69 & $\mathrm{Up}$ \\
\hline ENST00000484567 & 0.004827 & 2.7 & $\mathrm{Up}$ \\
\hline ENST00000529334 & 0.006399 & 2.7 & Up \\
\hline ENST00000462814 & 0.024536 & 2.71 & $\mathrm{Up}$ \\
\hline ENST00000512214 & 0.001719 & 2.72 & Up \\
\hline ENST00000597336 & 0.002131 & 2.72 & Up \\
\hline ENST00000513044 & 0.002454 & 2.73 & Up \\
\hline ENST00000462264 & 0.002692 & 2.73 & Up \\
\hline FR0069759 & 0.006313 & 2.74 & Up \\
\hline ENST00000536823 & 0.031865 & 2.74 & Up \\
\hline NONHSAT079829 & 0.004599 & 2.75 & Up \\
\hline NONHSAT103651 & 0.011939 & 2.75 & $\mathrm{Up}$ \\
\hline ENST00000464026 & 0.002435 & 2.76 & $\mathrm{Up}$ \\
\hline ENST00000466287 & 0.012798 & 2.77 & Up \\
\hline ENST00000524936 & 0.040883 & 2.77 & $\mathrm{Up}$ \\
\hline NONHSAT015408 & 0.001016 & 2.78 & $\mathrm{Up}$ \\
\hline ENST00000555596 & 0.020474 & 2.79 & Up \\
\hline NONHSAT107508 & 0.040523 & 2.81 & Up \\
\hline ENST00000505252 & 0.003757 & 2.82 & Up \\
\hline ENST00000421480 & 0.004384 & 2.82 & Up \\
\hline NONHSAT000825 & 0.007246 & 2.82 & Up \\
\hline ENST00000436137 & 0.013414 & 2.84 & Up \\
\hline ENST00000600056 & 0.037878 & 2.84 & Up \\
\hline ENST00000477648 & 0.042366 & 2.84 & $\mathrm{Up}$ \\
\hline NONHSAT138537 & 0.021098 & 2.86 & Up \\
\hline ENST00000497638 & 0.002303 & 2.88 & Up \\
\hline ENST00000475697 & 0.011090 & 2.88 & $\mathrm{Up}$ \\
\hline ENST00000549100 & 0.013755 & 2.89 & Up \\
\hline ENST00000466522 & 0.001427 & 2.9 & Up \\
\hline ENST00000477648 & 0.001554 & 2.9 & Up \\
\hline ENST00000596267 & 0.000511 & 2.91 & Up \\
\hline ENST00000492497 & 0.005636 & 2.91 & Up \\
\hline ENST00000580010 & 0.016036 & 2.91 & Up \\
\hline ENST00000488850 & 0.000664 & 2.95 & Up \\
\hline ENST00000530163 & 0.001084 & 2.95 & $\mathrm{Up}$ \\
\hline ENST00000548283 & 0.002213 & 2.95 & Up \\
\hline ENST00000480707 & 0.003638 & 2.95 & Up \\
\hline ENST00000588390 & 0.003598 & 2.97 & Up \\
\hline ENST00000490265 & 0.004425 & 2.99 & $\mathrm{Up}$ \\
\hline
\end{tabular}

Table II. Continued.

\begin{tabular}{|c|c|c|c|}
\hline IncRNA_id & P-value & $\begin{array}{c}\text { Fold } \\
\text { change }\end{array}$ & $\begin{array}{l}\text { Upregulation or } \\
\text { downregulation }\end{array}$ \\
\hline NONHSAT103765 & 0.000385 & 3.01 & Up \\
\hline ENST00000565390 & 0.011921 & 3.02 & $\mathrm{Up}$ \\
\hline ENST00000482284 & 0.001966 & 3.03 & $\mathrm{Up}$ \\
\hline NONHSAT097185 & 0.014811 & 3.04 & $\mathrm{Up}$ \\
\hline NONHSAT006994 & 0.009113 & 3.06 & Up \\
\hline ENST00000592636 & 0.021185 & 3.06 & Up \\
\hline NONHSAT074169 & 0.003962 & 3.08 & $\mathrm{Up}$ \\
\hline ENST00000490258 & 0.013133 & 3.08 & $\mathrm{Up}$ \\
\hline NONHSAT017862 & 0.000362 & 3.11 & Up \\
\hline NONHSAT 103002 & 0.008231 & 3.11 & $\mathrm{Up}$ \\
\hline ENST00000476635 & 0.000925 & 3.15 & Up \\
\hline ENST00000494618 & 0.011662 & 3.19 & $\mathrm{Up}$ \\
\hline ENST00000471892 & 0.019328 & 3.21 & $\mathrm{Up}$ \\
\hline ENST00000483207 & 0.024033 & 3.21 & $\mathrm{Up}$ \\
\hline ENST00000514842 & 0.000120 & 3.24 & Up \\
\hline ENST00000486261 & 0.001738 & 3.24 & $\mathrm{Up}$ \\
\hline ENST00000585864 & 0.035171 & 3.24 & Up \\
\hline ENST00000434942 & 0.008521 & 3.26 & $\mathrm{Up}$ \\
\hline ENST00000564690 & 0.001087 & 3.27 & $\mathrm{Up}$ \\
\hline NONHSAT122723 & 0.000366 & 3.28 & Up \\
\hline ENST00000479971 & 0.017701 & 3.31 & Up \\
\hline ENST00000534296 & 0.001884 & 3.32 & $\mathrm{Up}$ \\
\hline ENST00000510321 & 0.009749 & 3.32 & Up \\
\hline NONHSAT065985 & 0.002444 & 3.34 & $\mathrm{Up}$ \\
\hline ENST00000552938 & 0.021853 & 3.35 & Up \\
\hline NONHSAT076663 & 0.001175 & 3.36 & Up \\
\hline ENST00000506675 & 0.002164 & 3.38 & $\mathrm{Up}$ \\
\hline NONHSAT046699 & 0.002645 & 3.41 & $\mathrm{Up}$ \\
\hline ENST00000472297 & 0.021161 & 3.47 & Up \\
\hline ENST00000554812 & 0.000307 & 3.51 & $\mathrm{Up}$ \\
\hline ENST00000506067 & 0.000610 & 3.56 & Up \\
\hline NONHSAT023366 & 0.002519 & 3.59 & Up \\
\hline ENST00000481407 & 0.004871 & 3.68 & $\mathrm{Up}$ \\
\hline ENST00000498815 & 0.000260 & 3.72 & Up \\
\hline NONHSAT113228 & 0.032323 & 3.75 & Up \\
\hline ENST00000559075 & 0.000676 & 3.76 & $\mathrm{Up}$ \\
\hline NONHSAT081217 & 0.002130 & 3.77 & Up \\
\hline ENST00000479757 & 0.001441 & 3.82 & Up \\
\hline ENST00000452181 & 0.001118 & 4.09 & $\mathrm{Up}$ \\
\hline NONHSAT008483 & 0.022491 & 4.38 & Up \\
\hline ENST00000506214 & 0.000043 & 5.39 & Up \\
\hline
\end{tabular}

more $\mathrm{CD} 44^{+} \mathrm{CD} 24^{-}$phenotype cells. These results were consistent with previous studies (38-40), and confirmed that the platform worked well. Subsequently, the expression profile of IncRNAs in BCSCs with the CD $44^{+} \mathrm{CD} 24^{-}$phenotype was investigated via microarray analysis. To the best of our knowledge, the present study was the first to 
A
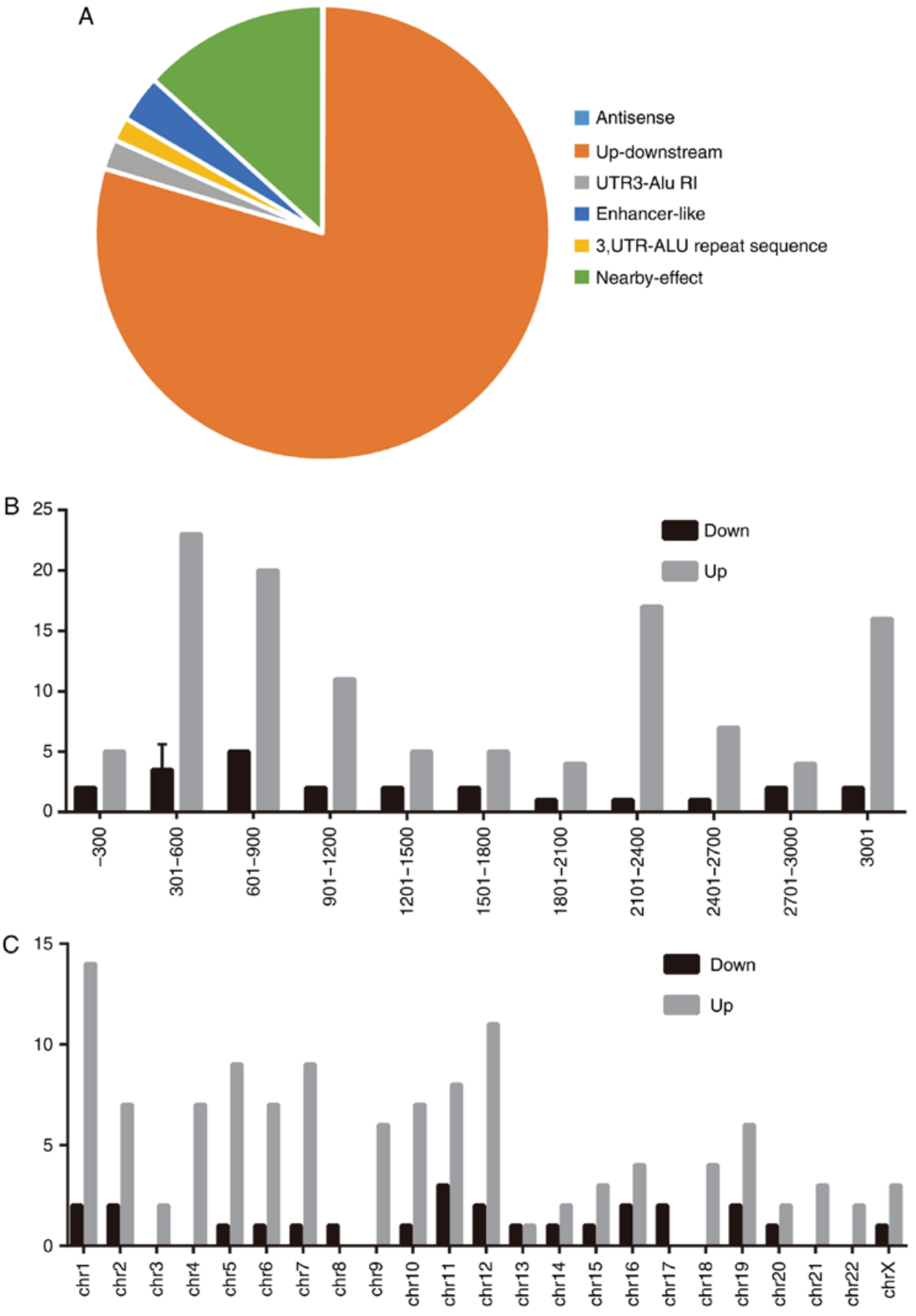

Figure 3. Classification of aberrantly expressed lncRNAs in BCSCs. (A) Most lncRNAs were located up-downstream from their counterpart mRNAs. (B) These lncRNAs were mainly 301-600 and 601-900 nucleotides in length. (C) Dysregulated lncRNAs were located on different chromosomes. BCSC, breast cancer stem cell; lncRNA, long non-coding RNA; UTR, untranslated region; chr, chromosome.

report the IncRNA profile of BCSCs. In the present study, 142 IncRNAs were aberrantly expressed in CD44+CD24 BCSCs compared with in non-BCSCs. Importantly, among the 142 lncRNAs identified, 117 lncRNAs were upregulated and 25 were downregulated. In addition, six of these lncRNAs were randomly selected to be verified by qPCR. The qPCR findings supported the microarray results. A previous study has demonstrated that lncRNAs are involved in the potency and differentiation of mammalian embryonic and adult stem cells (41). For example, it has been reported that the H19 expression level is lower in mesenchymal stem cells that will differentiate into adipocytes compared with in non-mesenchymal stem cells (42). These data revealed that the grade of differentiation was associated with lncRNAs. Therefore, the present data demonstrated that cancer stem cells have a different IncRNA profile when compared with non-cancer stem cells, this at least partially agrees with previous results $(41,42)$.

Currently, due to dramatic advances in bioinformatics and sequencing technologies, an increasing number of lncRNAs have been identified. However, only a small fraction of the discovered lncRNAs have been functionally annotated. Generally, the functions of lncRNAs are predicted through their counterpart mRNAs. In the present study, GO and 
A
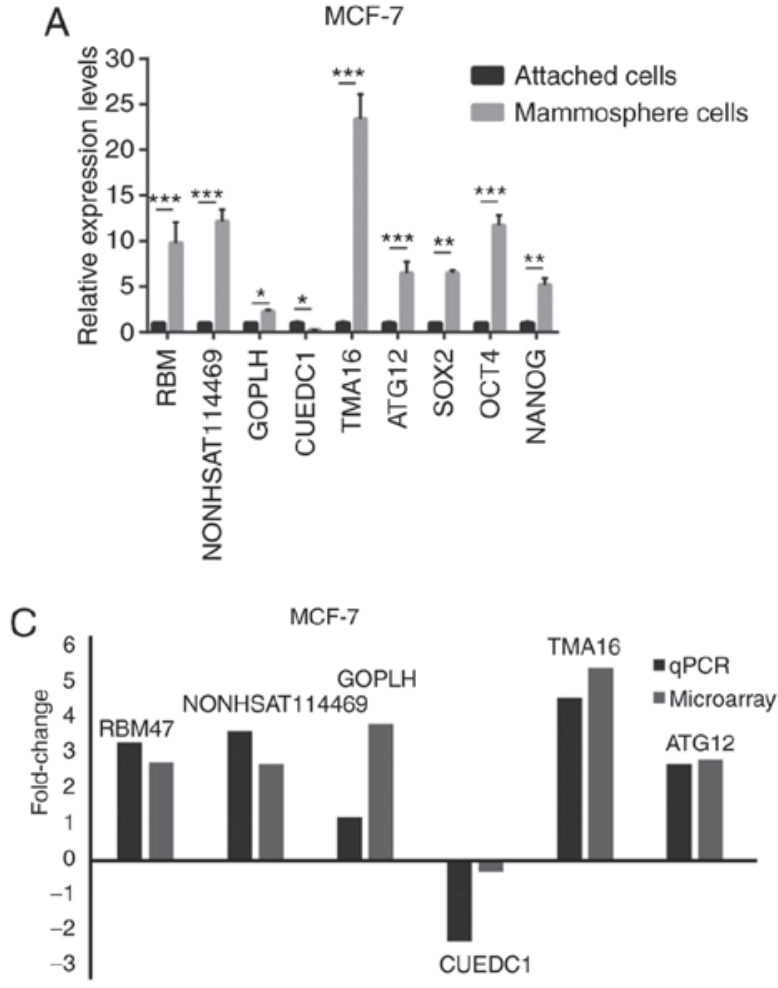

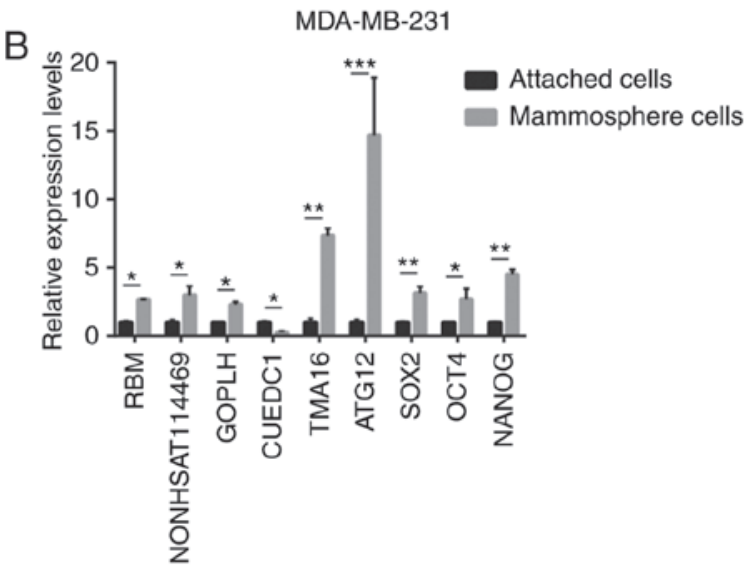

D

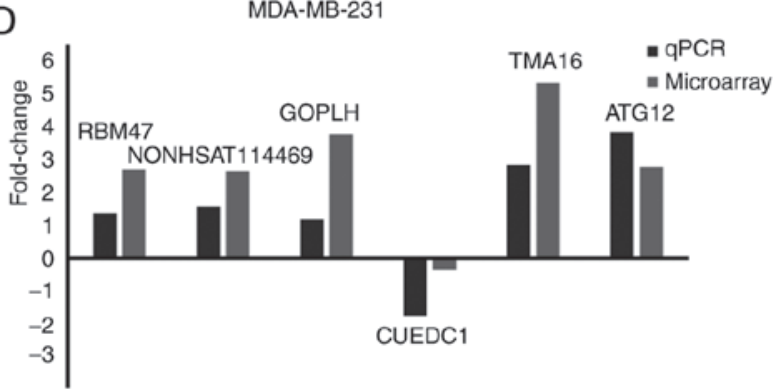

Figure 4. qPCR validation of the differences in the expression of six lncRNAs, SOX2, NANOG and OCT4 between BCSCs and non-BCSCs. (A) Expression levels of six lncRNAs, SOX2, NANOG and OCT4 in adherent cells and floating mammospheres derived from MCF7 cells. (B) Expression levels of six IncRNAs, SOX2, NANOG and OCT4 in adherent cells and floating mammospheres derived from the MDA-MB-231 cell line. (C) Comparison of the microarray data and qPCR results in MCF7 cells. (D) Comparison of the microarray data and qPCR results in MDA-MB231 cells. The y-axis shows the average fold change (log2 transformed) for each lncRNA measured by qPCR and microarray analysis. ${ }^{*} \mathrm{P}<0.05,{ }^{* * *} \mathrm{P}<0.01$ and ${ }^{* * * *} \mathrm{P}<0.001$, as indicated. qPCR, quantitative PCR; BCSC, breast cancer stem cell; lncRNA, long non-coding RNA.

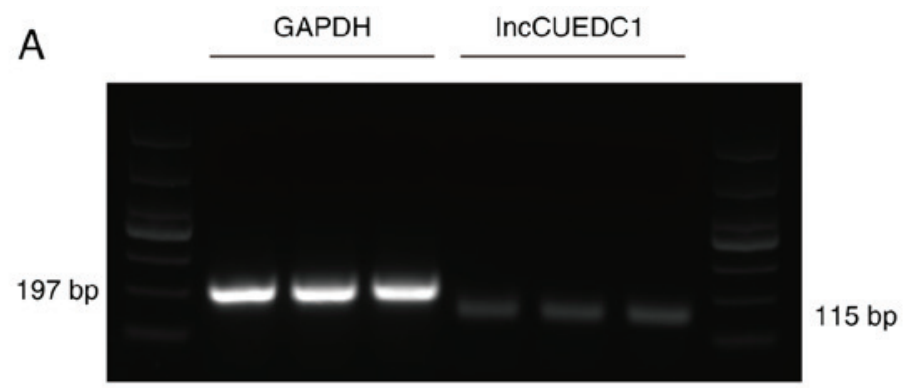

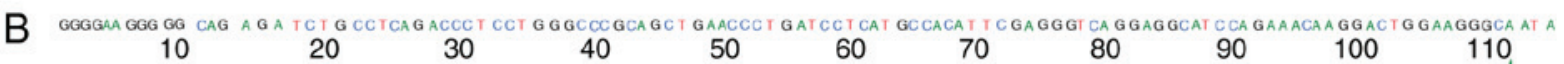

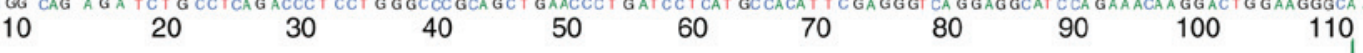

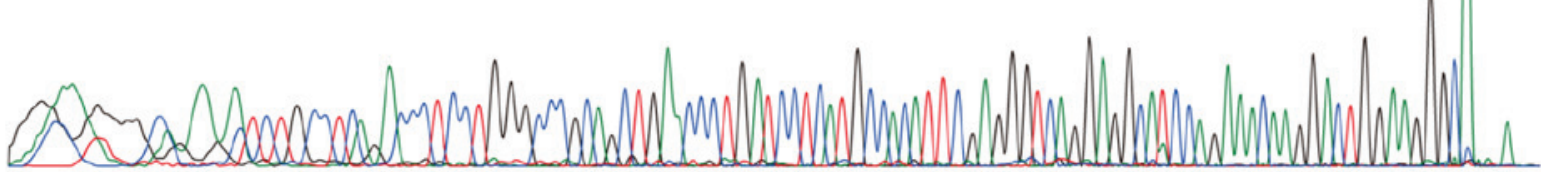

Figure 5. PCR and Sanger sequencing validation of lncCUEDC1. (A) Gel electrophoresis results. (B) Sanger sequencing results. lncCUEDC1, long non-coding RNA CUE domain containing 1.

KEGG pathway analyses were performed to predict the potential roles of the screened lncRNAs. GO analysis demonstrated that the most frequently enriched functions of lncRNAs were 'transcription', 'regulation of transcription', 'small molecule 

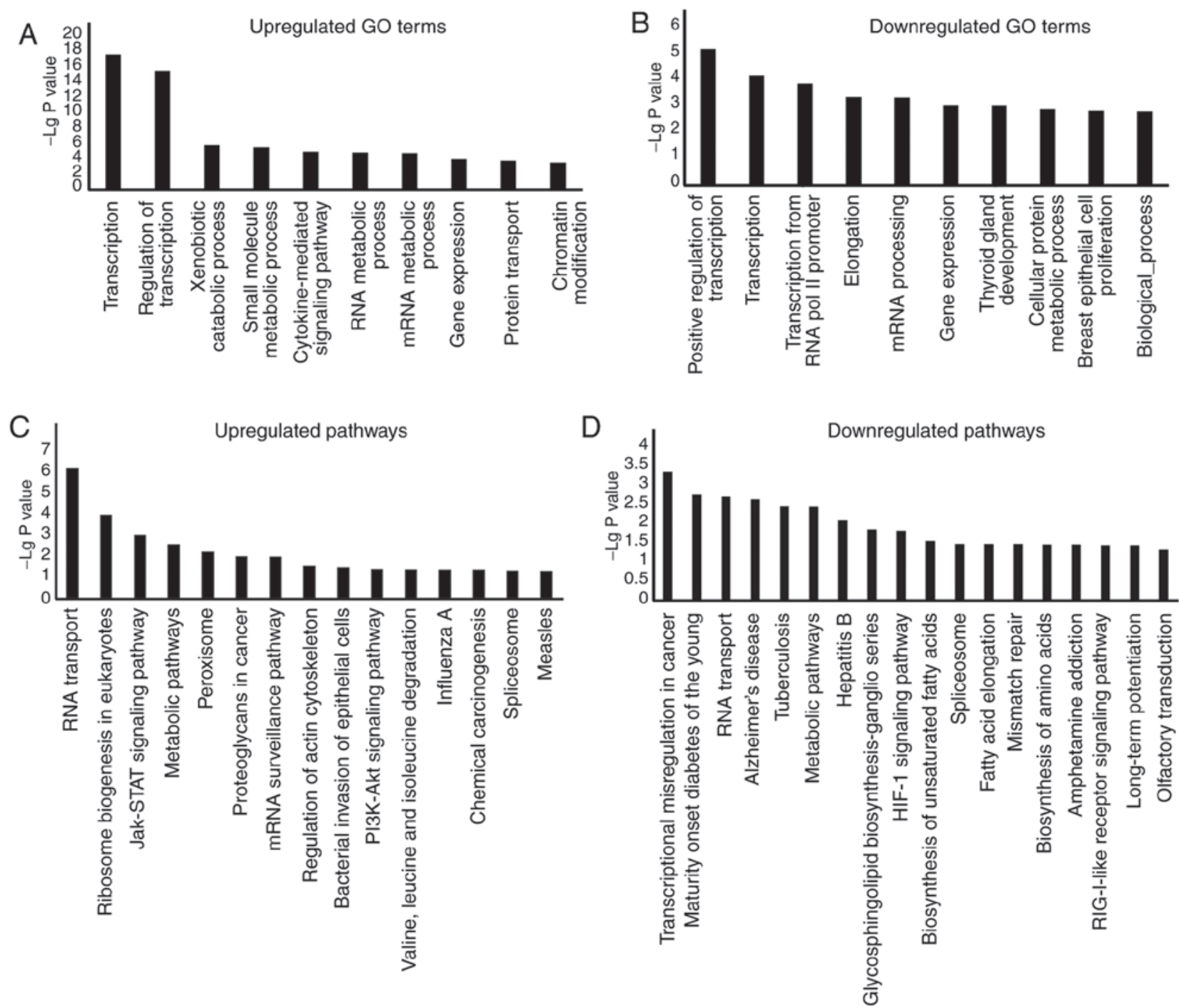

Figure 6. GO and KEGG pathway analyses. (A) Upregulated and (B) downregulated GO enrichment terms. (C) Upregulated and (D) downregulated KEGG pathways. GO, Gene Ontology; KEGG, Kyoto Encyclopedia of Genes and Genomes.

metabolic process' and 'cytokine-mediated signaling pathway'. These results indicated that the IncRNAs detected here may be involved in controlling BCSCs at the transcriptional and translational levels to some extent. Additionally, KEGG pathway analysis revealed that the 'JAK-STAT signaling pathway', 'PI3K-Akt pathway' and 'HIF-1 signaling pathway' were among the top predicted pathways. These pathways have been demonstrated to be involved in regulating the behaviors of CSCs $(31,33,43)$. Therefore, it is reasonable to postulate that these lncRNAs are likely to be involved in modulating these pathways. These findings provided a direction for further exploration of the functional roles of lncRNAs in BCSCs.

The functionalities of IncRNAs in BCSCs remain unknown. A previous report has revealed that lncRNAs are capable of regulating the expression of nearby protein coding genes via chromatin modification, transcription and post-transcriptional processing (44). One of the most reported function patterns for lncRNAs is chromatin modification. For example, HOTAIR is able to suppress transcription by recruiting an inhibitory chromatin state (45). Furthermore, a pivotal role served by lncRNAs in regulating transcription is associated with enhancers (46) and promoters (47), as demonstrated by the well-characterized lncRNA CCAT1-L. Xiang et al (48) concluded that CCAT1-L is encoded within an enhancer positioned $515 \mathrm{~kb}$ upstream from the MYC gene, and they found that it could enhance the expression of MYC and promote tumorigenesis. In addition, IncRNAs generated from antisense transcripts are possibly involved in the control of mRNA dynamics in post-transcriptional process (49). In the present study, a lncRNA-mRNA network was constructed based on the abovementioned functions. The network provided evidence to better illustrate the functional mechanisms of lncRNAs.

The IncRNA-mRNA network analysis revealed that lncCUEDC1 was substantially downregulated and may be able to interact with MSI2. However, the potential roles in BCSCs were undetermined. Hence, siRNAs were designed to knockdown the expression of lncCUEDC1 and explore its effects on stemness of BCSCs in vitro. Nanog, Sox 2 and Oct 4 are key transcription factors for maintaining self-renewal capacity and stemness (41). Therefore, the abundance of stemness-related markers, including Nanog, Sox 2 and 
A

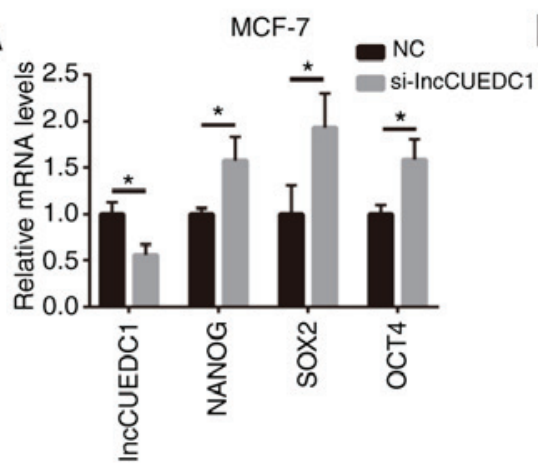

B
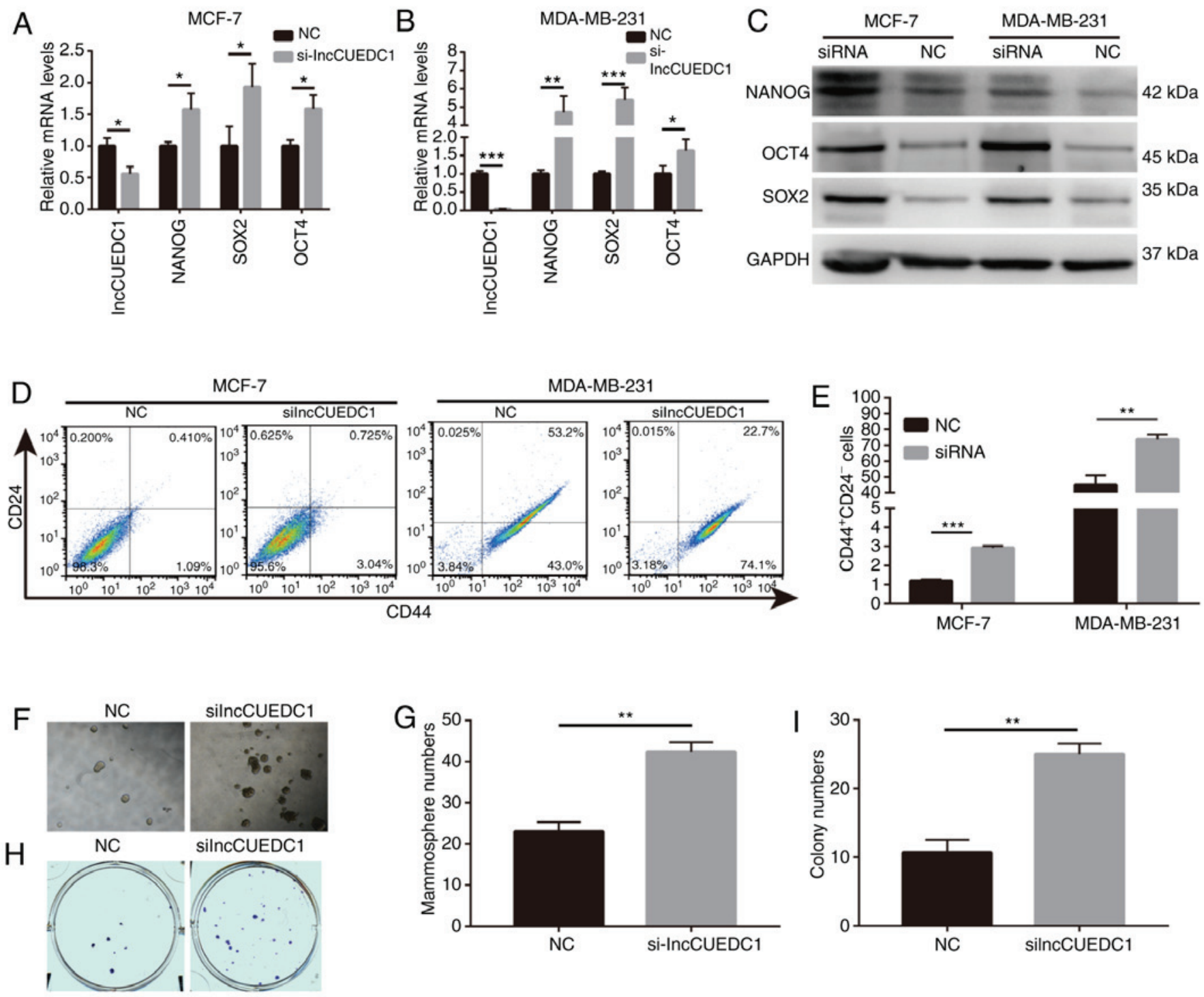

Figure 7. lncCUEDC1 negatively regulates BCSCs in vitro. (A) mRNA expression levels of NANOG, SOX2 and OCT4 were markedly increased following loss of 1ncCUEDC1 in MCF-7 cells. (B) mRNA expression levels of NANOG, SOX2 and OCT4 were markedly increased following loss of lncCUEDC1 in MDA-MB-231 cells. (C) Protein expression levels of NANOG, SOX2 and OCT4 were markedly increased following loss of lncCUEDC1 in MCF-7 and MDA-MB-231 cells. (D) Flow cytometry revealed that CD44 ${ }^{+}$CD24- putative BCSCs were largely expanded after loss of lncCUEDC1 in vitro. (E) When the breast cancer cells were treated with lncCUEDC1 siRNA for $48 \mathrm{~h}$, the proportions of CD44+CD24 putative BCSCs were largely increased compared with cells treated with the NC. (F) Size of mammospheres was enhanced after loss of lncCUEDC1. (G) Numbers of mammospheres were enhanced after loss of lncCUEDC1. (H) lncCUEDC1 depletion increased the size of colonies. (I) lncCUEDC1 depletion increased the numbers of colonies. All results were obtained from three independent experiments, and the data are presented as the mean $\pm \mathrm{SD}$. ${ }^{*} \mathrm{P}<0.05,{ }^{* *} \mathrm{P}<0.01$ and ${ }^{* * * *} \mathrm{P}<0.001$, as indicated. lncCUEDC1, long non-coding RNA CUE domain containing 1; BCSC, breast cancer stem cell; NC, negative control; siRNA, small interfering RNA.

Oct4 was also examined. The data demonstrated that the stemness-related factors were increased at both the mRNA and protein levels when the expression of 1 ncCUEDC1 was knocked down. According to the BCSC concept, breast cancer is derived from a small fraction of breast cancer cells with the $\mathrm{CD} 44^{+} \mathrm{CD} 24^{-}$phenotype (50). Therefore, the impact of lncCUEDC1 on the BCSC phenotype was examined. The results demonstrated that the proportion of $\mathrm{CD} 44^{+} \mathrm{CD} 24^{-}$cells in MCF7 and MDA-MB-231 breast cancer cells was enhanced substantially after the loss of 1ncCUEDC1 expression. In addition, loss of lncCUEDC1 could increase the self-renewal capacity of BCSCs in mammosphere and colony formation assays. These results indicated that 1 cCUEDC1 was a potential inhibitor of the stemness of BCSCs. Although the present study suggested that 1ncCUEDC1 served a suppressive role in BCSCs, the possibility that other dysregulated lncRNAs are also involved in controlling BCSCs has not been excluded since only cell samples were screened. The function of lncRNAs is closely associated with their intracellular localization. IncRNAs located in the cytoplasm mainly serve as microRNA sponges to regulate target gene expression; however, lncRNAs located in the nucleus tend to be involved in chromatin remodeling and epigenetic modification $(17,51)$. The FISH assay results revealed that lncCUEDC1 was not only mainly located in the nucleus, but also co-located with Nanog in the nucleus. Furthermore, the luciferase reporter assay results revealed that Nanog expression was decreased when lncCUEDC1 was overexpressed. Our previous study 

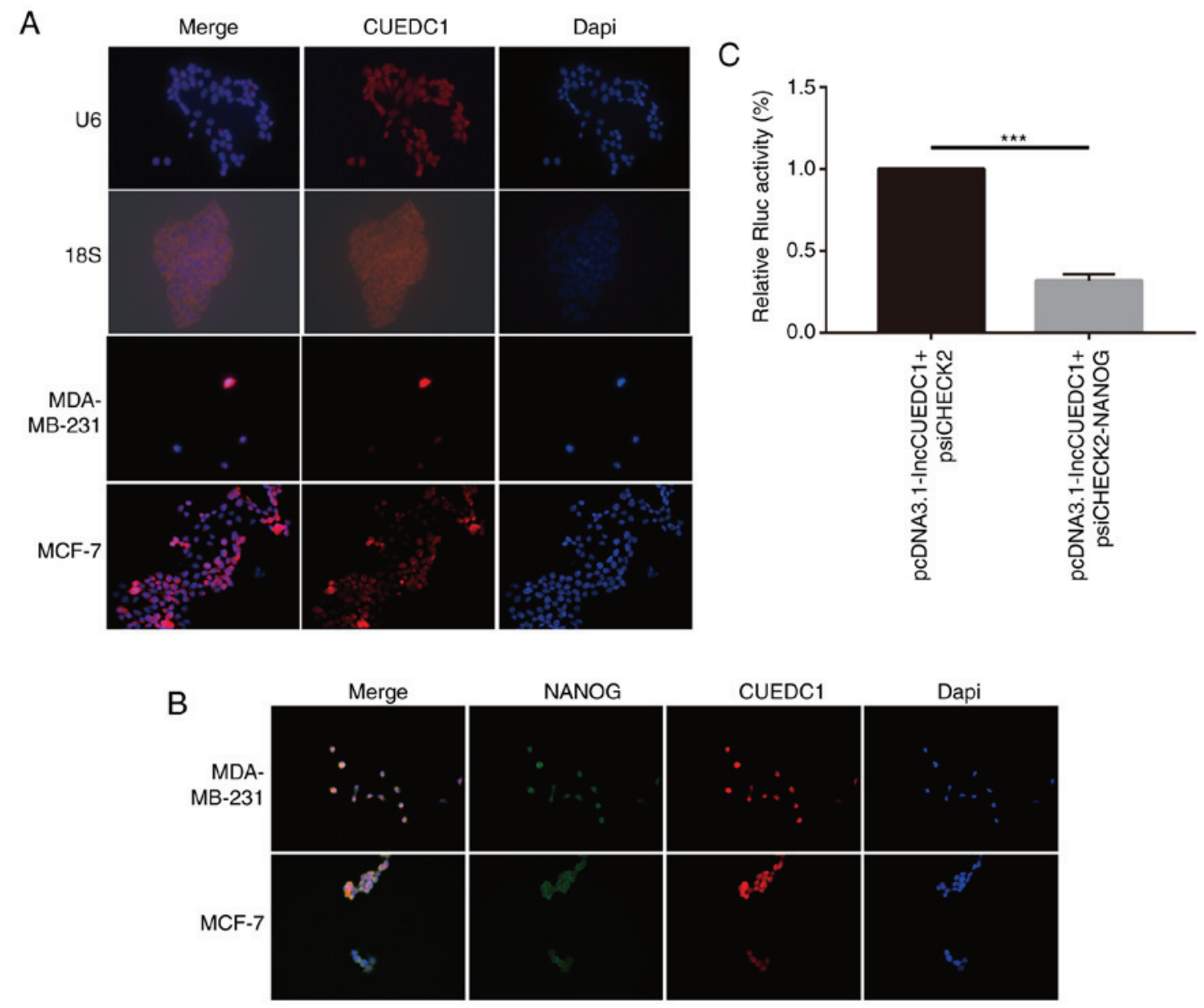

Figure 8. IncCUEDC1 co-localizes with NANOG in the nucleus and inhibits the expression of NANOG. (A) lncCUEDC1 was located in the nucleus in breast cancer cells. (B) lncCUEDC1 could co-localize with Nanog in the nucleus. (C) Forced lncCUEDC1 expression could effectively decrease the expression of Nanog. Data are presented as the mean \pm SD. ${ }^{* * *} \mathrm{P}<0.001$. lncCUEDC1, long non-coding RNA CUE domain containing 1; Rluc, Renilla luciferase.

demonstrated that Nanog depletion could inhibit the stemness of breast cancer cells (35). Hence, collectively, these data suggest that lncCUEDC1 may inhibit stemness by suppressing the expression of Nanog. However, further investigation is required.

In conclusion, the present study revealed the lncRNA profile in BCSCs for the first time as determined by microarray analysis. Overall, 117 upregulated lncRNAs and 25 downregulated lncRNAs were identified between BCSCs and non-BCSCs. In addition, a lncRNA-mRNA interaction network was constructed. Notably, lncCUEDC1 was the most downregulated, and loss of function assays demonstrated that lncCUEDC1 was a negative modulator for the maintenance of stemness in BCSCs. Mechanistically, the present study demonstrated that lncCUEDC1 may inhibit BCSC stemness by reducing Nanog expression. These findings provide evidence that lncCUEDC1 may possess a considerable potential as a therapeutic target in BCSCs.

\section{Acknowledgements}

The authors would like to thank Professor Yanyun Zhang at the Institute of Health Sciences, Shanghai Institutes for Biological Sciences for providing equipment and excellent technical support.

\section{Funding}

The present study was funded by the National Natural Science Foundation of China (grant nos. 81172522 and 81301858) and the Suzhou Science and Technology Project (grant nos. SYS201508 and SYS201308).

\section{Availability of data and materials}

The datasets used and/or analyzed during the current study are available from the corresponding author on reasonable request.

\section{Authors' contributions}

NY and YX developed the concept. FZ, YM and LX developed the methods. FZ, YM, LX and HX performed formal analysis. FZ and YM wrote the original draft. NY and YX reviewed and edited the manuscript. NY and YX provided supervision. FZ, YM and LX were involved in project administration. FZ and YX acquired funding. All authors read and approved the final manuscript.

\section{Ethics approval and consent to participate}

Not applicable. 


\section{Patient consent for publication}

Not applicable.

\section{Competing interests}

The authors declare that they have no competing interests.

\section{References}

1. Siegel RL, Miller KD and Jemal A: Cancer statistics, 2016. CA Cancer J Clin 66: 7-30, 2016.

2. Reya T, Morrison SJ, Clarke MF and Weissman IL: Stem cells, cancer, and cancer stem cells. Nature 414: 105-111, 2001.

3. Liu R, Wang X, Chen GY, Dalerba P, Gurney A, Hoey T, Sherlock G, Lewicki J, Shedden K and Clarke MF: The prognostic role of a gene signature from tumorigenic breast-cancer cells. N Engl J Med 356: 217-226, 2007.

4. Samanta D, Gilkes DM, Chaturvedi P, Xiang L and Semenza GL: Hypoxia-inducible factors are required for chemotherapy resistance of breast cancer stem cells. Proc Natl Acad Sci USA 111: E5429-E5438, 2014

5. De Los Angeles A, Ferrari F, Xi R, Fujiwara Y, Benvenisty N, Deng H, Hochedlinger K, Jaenisch R, Lee S, Leitch HG, et al Hallmarks of pluripotency. Nature 525: 469-478, 2015.

6. Graziano A, d'Aquino R, Tirino V, Desiderio V, Rossi A and Pirozzi G: The stem cell hypothesis in head and neck cancer. J Cell Biochem 103: 408-412, 2008.

7. Malhotra GK, Zhao X, Band H and Band V: Shared signaling pathways in normal and breast cancer stem cells. J Carcinog 10: 38, 2011 .

8. El Helou R, Pinna G, Cabaud O, Wicinski J, Bhajun R, Guyon L, Rioualen C, Finetti P, Gros A, Mari B, et al: miR-600 acts as a bimodal switch that regulates breast cancer stem cell fate through WNT signaling. Cell Rep 18: 2256-2268, 2017.

9. Bouras T, Pal B, Vaillant F, Harburg G, Asselin-Labat ML, Oakes SR, Lindeman GJ and Visvader JE: Notch signaling regulates mammary stem cell function and luminal cell-fate commitment. Cell Stem Cell 3: 429-441, 2008.

10. Liu S, Dontu G, Mantle ID, Patel S, Ahn NS, Jackson KW, Suri $\mathrm{P}$ and Wicha MS: Hedgehog signaling and Bmi-1 regulate self-renewal of normal and malignant human mammary stem cells. Cancer Res 66: 6063-6071, 2006.

11. Bertone P, Stolc V, Royce TE, Rozowsky JS, Urban AE, Zhu X, Rinn JL, Tongprasit W, Samanta M, Weissman S, et al: Global identification of human transcribed sequences with genome tiling arrays. Science 306: 2242-2246, 2004.

12. Ponting CP, Oliver PL and Reik W: Evolution and functions of long noncoding RNAs. Cell 136: 629-641, 2009.

13. Fatica A and Bozzoni I: Long non-coding RNAs: New players in cell differentiation and development. Nat Rev Genet 15: 7-21, 2014.

14. Hu X, Feng Y, Zhang D, Zhao SD, Hu Z, Greshock J, Zhang Y, Yang L, Zhong X, Wang LP, et al: A functional genomic approach identifies FAL1 as an oncogenic long noncoding RNA that associates with BMI1 and represses p21 expression in cancer. Cancer Cell 26: 344-357, 2014.

15. Xu C, Yang M, Tian J, Wang X and Li Z: MALAT-1: A long non-coding RNA and its important 3 ' end functional motif in colorectal cancer metastasis. Int J Oncol 39: 169-175, 2011.

16. Lin A, Li C, Xing Z, Hu Q, Liang K, Han L, Wang C, Hawke DH, Wang S, Zhang Y, et al: The LINK-A lncRNA activates normoxic HIFl $\alpha$ signalling in triple-negative breast cancer. Nat Cell Biol 18: 213-224, 2016.

17. Guttman M, Amit I, Garber M, French C, Lin MF, Feldser D, Huarte M, Zuk O, Carey BW, Cassady JP, et al: Chromatin signature reveals over a thousand highly conserved large non-coding RNAs in mammals. Nature 458: 223-227, 2009.

18. Liu B, Sun L, Liu Q, Gong C, Yao Y, Lv X, Lin L, Yao H, Su F, $\mathrm{Li} \mathrm{D}$, et al: A cytoplasmic NF- $\mathrm{BB}$ interacting long noncoding RNA blocks I $\kappa \mathrm{B}$ phosphorylation and suppresses breast cancer metastasis. Cancer Cell 27: 370-381, 2015.

19. Gupta RA, Shah N, Wang KC, Kim J, Horlings HM, Wong DJ, Tsai MC, Hung T, Argani P, Rinn JL, et al: Long non-coding RNA HOTAIR reprograms chromatin state to promote cancer metastasis. Nature 464: 1071-1076, 2010.
20. Huang J, Zhou N, Watabe K, Lu Z, Wu F, Xu M and Mo YY: Long non-coding RNA UCA1 promotes breast tumor growth by suppression of p27 (Kip1). Cell Death Dis 5: e1008, 2014.

21. Mourtada-Maarabouni M, Pickard MR, Hedge VL, Farzaneh F and Williams GT: GAS5, a non-protein-coding RNA, controls apoptosis and is downregulated in breast cancer. Oncogene 28: 195-208, 2009.

22. Yan N, Xu L, Wu X, Zhang L, Fei X, Cao Y and Zhang F: GSKJ4, an H3K27me3 demethylase inhibitor, effectively suppresses the breast cancer stem cells. Exp Cell Res 359: 405-414, 2017.

23. Zhang X, Wu D, Chen L, Li X, Yang J, Fan D, Dong T, Liu M, Tan P, Xu J, et al: RAID: A comprehensive resource for human RNA-associated (RNA-RNA/RNA-protein) interaction. RNA 20: 989-993, 2014.

24. Pujana MA, Han JD, Starita LM, Stevens KN, Tewari M, Ahn JS, Rennert G, Moreno V, Kirchhoff T, Gold B, et al: Network modeling links breast cancer susceptibility and centrosome dysfunction. Nat Genet 39: 1338-1349, 2007.

25. Livak KJ and Schmittgen TD: Analysis of relative gene expression data using real-time quantitative PCR and the 2(-Delta Delta C(T)) method. Methods 25: 402-408, 2001.

26. Ponti D, Costa A, Zaffaroni N, Pratesi G, Petrangolini G, Coradini D, Pilotti S, Pierotti MA and Daidone MG: Isolation and in vitro propagation of tumorigenic breast cancer cells with stem/progenitor cell properties. Cancer Res 65: 5506-5511, 2005.

27. Xu N, Wang F, Lv M and Cheng L: Microarray expression profile analysis of long non-coding RNAs in human breast cancer: A study of Chinese women. Biomed Pharmacother 69: 221-227, 2015.

28. Sun J, Lin $\mathrm{Y}$ and $\mathrm{Wu} \mathrm{J}$ : Long non-coding RNA expression profiling of mouse testis during postnatal development. PLoS One 8: e75750, 2013.

29. Guenzl PM and Barlow DP: Macro lncRNAs: A new layer of cis-regulatory information in the mammalian genome. RNA Biol 9: 731-741, 2012.

30. Gong X, Wei W, Chen L, Xia Z and Yu C: Comprehensive analysis of long non-coding RNA expression profiles in hepatitis B virus-related hepatocellular carcinoma. Oncotarget 7: 42422-42430, 2016.

31. Hernandez-Vargas H, Ouzounova M, Le Calvez-Kelm F, Lambert MP, McKay-Chopin S, Tavtigian SV, Puisieux A, Matar C and Herceg Z: Methylome analysis reveals Jak-STAT pathway deregulation in putative breast cancer stem cells. Epigenetics 6: 428-439, 2011.

32. Almozyan S, Colak D, Mansour F, Alaiya A, Al-Harazi O, Qattan A, Al-Mohanna F, Al-Alwan M and Ghebeh H: PD-L1 promotes OCT4 and Nanog expression in breast cancer stem cells by sustaining PI3K/AKT pathway activation. Int J Cancer 141: 1402-1412, 2017

33. Chanmee T, Ontong P, Izumikawa T, Higashide M, Mochizuki N, Chokchaitaweesuk C, Khansai M, Nakajima K, Kakizaki I, Kongtawelert $\mathrm{P}$, et al: Hyaluronan production regulates metabolic and cancer stem-like properties of breast cancer cells via hexosamine biosynthetic pathway-coupled HIF-1 signaling. J Biol Chem 291: 24105-24120, 2016.

34. Sahu D, Hsu CL, Lin CC, Yang TW, Hsu WM, Ho SY, Juan HF and Huang HC: Co-expression analysis identifies long noncoding RNA SNHG1 as a novel predictor for event-free survival in neuroblastoma. Oncotarget 7: 58022-58037, 2016.

35. Hu C, Xu L, Liang S, Zhang Z, Zhang Y and Zhang F: Lentivirus-mediated shRNA targeting Nanog inhibits cell proliferation and attenuates cancer stem cell activities in breast cancer. J Drug Target 24: 422-432, 2016.

36. Berteaux N, Lottin S, Monté D, Pinte S, Quatannens B, Coll J, Hondermarck H, Curgy JJ, Dugimont T and Adriaenssens E: H19 mRNA-like noncoding RNA promotes breast cancer cell proliferation through positive control by E2F1. J Biol Chem 280: 29625-29636, 2005.

37. Hou P, Zhao Y, Li Z, Yao R, Ma M, Gao Y, Zhao L, Zhang Y, Huang B and Lu J: LincRNA-ROR induces epithelial-to-mesenchymal transition and contributes to breast cancer tumorigenesis and metastasis. Cell Death Dis 5: e1287, 2014.

38. Ricardo S, Vieira AF, Gerhard R, Leitão D, Pinto R, Cameselle-Teijeiro JF, Milanezi F, Schmitt F and Paredes J: Breast cancer stem cell markers CD44, CD24 and ALDH1: Expression distribution within intrinsic molecular subtype. J Clin Pathol 64: 937-946, 2011. 
39. Honeth G, Bendahl PO, Ringnér M, Saal LH, GruvbergerSaal SK, Lövgren K, Grabau D, Fernö M, Borg A and Hegardt C: The CD44+/CD24- phenotype is enriched in basal-like breast tumors. Breast Cancer Res 10: R53, 2008.

40. Xu L, Zhang L, Hu C, Liang S, Fei X, Yan N, Zhang Y and Zhang F: WNT pathway inhibitor pyrvinium pamoate inhibits the self-renewal and metastasis of breast cancer stem cells. Int J Oncol 48: 1175-1186, 2016.

41. Sheik Mohamed J, Gaughwin PM, Lim B, Robson P and Lipovich L: Conserved long noncoding RNAs transcriptionally regulated by Oct4 and Nanog modulate pluripotency in mouse embryonic stem cells. RNA 16: 324-337, 2010.

42. Huang Y, Zheng Y, Jin C, Li X, Jia L and Li W: Long non-coding RNA H19 inhibits adipocyte differentiation of bone marrow mesenchymal stem cells through epigenetic modulation of histone deacetylases. Sci Rep 6: 28897, 2016.

43. Hu Y, Guo R, Wei J, Zhou Y, Ji W, Liu J, Zhi X and Zhang J: Effects of PI3K inhibitor NVP-BKM120 on overcoming drug resistance and eliminating cancer stem cells in human breast cancer cells. Cell Death Dis 6: e2020, 2015.

44. Mercer TR, Dinger ME and Mattick JS: Long non-coding RNAs: Insights into functions. Nat Rev Genet 10: 155-159, 2009.
45. Morris KV, Santoso S, Turner AM, Pastori C and Hawkins PG: Bidirectional transcription directs both transcriptional gene activation and suppression in human cells. PLoS Genet 4: e1000258, 2008.

46. Ashe HL, Monks J, Wijgerde M, Fraser P and Proudfoot NJ: Intergenic transcription and transinduction of the human beta-globin locus. Genes Dev 11: 2494-2509, 1997.

47. Guenther MG, Levine SS, Boyer LA, Jaenisch R and Young RA: A chromatin landmark and transcription initiation at most promoters in human cells. Cell 130: 77-88, 2007.

48. Xiang JF, Yin QF, Chen T, Zhang Y, Zhang XO, Wu Z, Zhang S, Wang HB, Ge J, Lu X, et al: Human colorectal cancer-specific CCAT1-L lncRNA regulates long-range chromatin interactions at the MYC locus. Cell Res 24: 513-531, 2014.

49. He Y, Vogelstein B, Velculescu VE, Papadopoulos N and Kinzler KW: The antisense transcriptomes of human cells. Science 322: 1855-1857, 2008.

50. Al-Hajj M, Wicha MS, Benito-Hernandez A, Morrison SJ and Clarke MF: Prospective identification of tumorigenic breast cancer cells. Proc Natl Acad Sci USA 100: 3983-3988, 2003.

51. Wang KC and Chang HY: Molecular mechanisms of long noncoding RNAs. Mol Cell 43: 904-914, 2011. 